\title{
Clinically relevant infections in hematology and oncology: bacterial infections and the role of novel antibiotics in times of multidrug resistance
}

\author{
Gernot Fritsche (D)
}

Received: 20 January 2021 / Accepted: 2 March 2021 / Published online: 1 April 2021

(C) The Author(s) 2021

\begin{abstract}
Summary Multidrug resistance of bacterial pathogens is an increasing problem wordwide, especially treatment of multidrug resistant (MDR) gramnegative bacteria is challenging. In the recent past, several new antibiotics as well as new betalactamase inhibitors have been introduced. These novel drugs are valuable new tools for the therapy of infectious complications in cancer patients once there is a high risk for infections due to multidrug-resistant pathogens. While it is necessary to start empirical antibiotic therapy immediately, novel antibiotics only provide benefits in certain situations, depending on the underlying pathogens. Thus, these new antibiotics are best used guided by microbiological testing, since the exact mechanism of resistance determines susceptibility or resistance to certain antibiotics. For empirical therapy, previous culture results and/or colonization with MDR pathogens can help to choose from conventional antibiotics or novel drugs. In clinical practice, optimal antibiotic therapy can be achieved by close collaboration of specialists in hematooncology, infectious diseases and microbiology.
\end{abstract}

Keywords New antibiotics - Microbiological testing · Multidrug resistance $\cdot$ Bacterial infections $\cdot$ Febrile neutropenia

\section{Abbreviations \\ BLI Betalactamase inhibitor \\ CABP Community-acquired bacterial pneumonia \\ cIAI Complicated intraabdominal infections \\ CRE Carbapenem-resistant enterobacteriaceae}

\section{PD Dr. G. Fritsche $(\bowtie)$}

Department of Internal Medicine II, Infectious Diseases,

Pneumology, Rheumatology, Medical University of

Innsbruck, Anichstrasse 35, 6020 Innsbruck, Austria

gernot.fritsche@i-med.ac.at
cUTI Complicated urinary infections

ESBL Extended spectrum betalactamase

HABP Hospital-acquired bacterial pneumonia

MBL Metallo-betalactamase

MDR Multidrug-resistant

MRSA Methicillin-resistant S. aureus

SSSI Skin and skin structure infections

TMP/ Trimethoprim-sulfamethoxazole

SMX

VABP Ventilator-associated bacterial pneumonia

VRE Vancomycin-resistant Enterococcus

\section{Introduction}

Patients with hematologic neoplasias and solid tumors are at increased risk for different kinds of infections due to both common and opportunistic pathogens. The most acute and clinically relevant problem is bacterial infections, which significantly contribute to morbidity and mortality in hematooncological patients. In addition, infections lead to delays and/or dose reductions of chemotherapeutics.

For febrile neutropenia, several guidelines have been published that cover all different aspects and provide good advice for the clinical management of this topic [1]. However, the epidemiology of pathogens responsible for bacterial infections is constantly evolving, with multidrug resistance being an increasingly common problem. Much less is known about the best possible treatment of multidrug resistant (MDR) bacteria in cancer patients. While a variety of novel antibiotics and/or combinations of antibiotics with new betalactamase inhibitors have been introduced, these new treatment options are not necessarily better and can even be less effective for the treatment of "standard pathogens". Thus, the aim of this article is to focus on the impact of multidrug 
resistance on the management of cancer patients with bacterial infections and discuss possible indications for the most important new antibiotic compounds as well as the putative downsides of novel therapeutics.

\section{Epidemiology}

In approximately half of patients with febrile neutropenia, the causative pathogen cannot be identified, so initial antibiotic treatment will often continue to be empirical. In high-risk patients, guidelines usually suggest the use of broad-spectrum betalactams with coverage of enterobacteriaceae, P. aerugiosa, S. aureus and Streptococci as first line agents. Thus, usually piperacillin/tazobactam, group 1 carbapenems (imipenem, meropenem) or pseudomonascephalosporins (cefepim, ceftazidim) are chosen as first-line antibiotics [1].

With the emergence of MDR pathogens, there is an increased risk of choosing the wrong initial empirical antibiotic therapy. While historically grampositive cocci have been the most prevalent pathogens in cancer patients, in recent years there has been a shift towards gramnegative bacteria [2]. The most common gramnegative bacteria isolated from bacteremia in patients with cancer are E. coli, P. aeruginosa, K. pneumoniae, Enterobacter spp. and, even more problematic to treat, Acinetobacter spp. and S. maltophilia. Staphylococci are most prevalent among grampositive bacteria, followed by Enterococci [3, 4]. These changes in epidemiology also have implications for treatment options. While there is a rather wide range of antibiotics available for the treatment of resistant grampositive bacteria, the treatment options for certain gramnegative pathogens are much more limited.

In fact, when MDR gramnegative bacilli could be identified as the causative pathogen, a study by Martinez-Nadal found that approximately $40 \%$ of neutropenic patients with bacteremia were treated with inappropriate empirical antibiotics, despite choosing treatment regimens suggested by international guidelines. This led to significantly higher mortality, especially in patients that initially presented with pneumonia, shock and with infections due to P. aeruginosa [3].

\section{Problematic pathogens}

The World Health Organization has defined a list of priority pathogens that are a major threat to human health due to their resistance profile and the limited availability of effective antibiotics. Many of these bacteria of critical or high priority are typically found as pathogens in patients with febrile neutropenia, i.e. extended spectrum betalactamase (ESBL)-producing or carbapenem-resistant enterobacteriaceae (CRE), carbapenem-resistant P. aeruginosa or Acinetobacter baumannii, as well as grampositive bacteria like methicillin-resistant or vancomycin-resistant S. aureus and vancomycin-resistant E. faecium. Knowledge of local epidemiology is important for the empirical choice of initial antibiotic therapy and whether to try to cover MDR bacteria before getting results from microbiological cultures. Furthermore, some clinical conditions are also correlated with increased incidence of MDR pathogens in neutropenic patients, i.e. duration of neutropenia, presence of indwelling central venous catheters and patient age [5]. To identify patients at risk for infections with MDR pathogens is even more relevant in critically ill patients, since inadequate empirical therapy results in higher mortality [6]. In clinical practice, the highest risk for the wrong choice of empirical therapy in neutropenic patients is given in bacteremia due to S. maltophilia, E. faecium, MDR-P. aeruginosa, coagulase-negative staphylococci and, to a less extent, ESBL E. coli [3].

\section{Extended spectrum betalactamase-expressing pathogens}

Infections due to ESBL-producing enterobacteriaceae are an increasingly common clinical problem in patients with chemotherapy-induced febrile neutropenia. At particular high risk are patients with leukemia, hepatobiliary cancer and patients with profound neutropenia [7]. Carbapenems are considered the therapy of choice; in blood stream infections with ESBL-E. coli and K. pneumoniae mortality was lower in patients treated with meropenem compared to piperacillin/ tazobactam [8].

\section{Carbapenem-resistant enterobacteriaceae}

CRE are of particular concern, as empirical antibiotic therapy with most betalactams will usually fail; targeted therapy will be delayed and only limited effective therapies are available. This leads to high mortality rates, especially in patients with leukemia and prolonged neutropenia. Besides local epidemiology, Lalaoui et al. described a number of risk factors for infections with CRE, namely male sex, middle age, acute leukemia, salvage chemotherapy, neutropenia and bowel colonization with CRE [6]. Microbiological samples with resistance testing are important for guided therapy; the effectiveness of antibiotics with novel betalactamase inhibitors depends on the type of carbapenemase involved [9]. Other treatment options include new tetracycline-derived antibiotics and older drugs like colistin, aminoglycosides and fosfomycin [10].

\section{Nonfermenters}

All of the most frequently diagnosed nonfermenters are difficult to treat microorganisms due to their intrinsic resistance to many antibiotics. First line therapy in febrile neutropenia usually consists in pseudomonas-active penicillins, cephalosporins or 
carbapenems [1]. Globally, MDR isolates are an increasing problem, in particular strains with efflux pumps or metallobetalactamases. The treatment of MDR pseudomonas should be guided by antimicrobial resistance testing. Possible therapies include antibiotic combinations with new betalactamase inhibtors, aminoglycosides, cefiderocol and colistin [9, 11]. For S. maltophilia, trimethoprim/ sulfamethoxazole (TMP/SMX) is considered the therapy of first choice. Depending on microbiological testing, fluoroquinolones can alternatively be used $[12,13]$. Among the new drugs, tetracycline derivatives and cefiderocol may be also be effective $[9,11$, 14].

A. baumannii is not a frequent cause of infections, but treatment is usually difficult and resistance to carbapenems is rising [15]. Alternative treatment options are new tetracyclins, cefiderocol and colistin $[9,16]$.

\section{Novel treatment options}

In the past few years, a number of new antibiotics have become available; some are combinations of old substances with novel betalactamase inhibitors, others are new members of existing antibiotic classes. The most relevant new additions to the antibiotic armamentarium are listed in Table 1.

\section{Betalactams}

Until recently, there have been almost no new drugs against MDR gramnegative bacteria, most commonly MDR enterobacteriaceae. This has changed now by introducing new combinations of betalactams with certain betalactamase inhibitors, some of which have a wider range of activity. In addition, new cephalosporins have been developed. The effectiveness of these drugs largely depends on the kind of betalactamase expressed by pathogens.

\section{Cephalosporins combined with betalactamase inhibitors}

Ceftolozan is a new cephalosporin with high activity against pseudomonas combined with an old betalactamase inhibitor (tazobactam), which confers stability against ESBL. On the other hand, ceftazidim is an old pseudomonas cephalosporin combined with a novel betalactamase inhibitor (avibactam). Avibactam accounts for stability against ESBL and certain carbapenemases (KPC, OXA). Both of the new drugs have poor activity against staphylococci, so they should be used carefully unless therapy can be guided by microbiological samples and resistance testing; alternatively they can be combined with an anti-staphylococcal drug. Both drugs have been approved and shown to be effective for the treatment of intraabdominal, urinary and pulmonary infections [17-19].

Table 1 New antibiotics: spectrum of antimicrobial activity, susceptible MDR pathogens and approved clinical indications

\begin{tabular}{|c|c|c|c|}
\hline \multicolumn{4}{|l|}{ Novel antibiotics } \\
\hline Drug (class) & Relevant pathogens usually covered (among others) & $\begin{array}{l}\text { Activity against MDR } \\
\text { pathogens }\end{array}$ & $\begin{array}{l}\text { Approved indica- } \\
\text { tions }\end{array}$ \\
\hline \multicolumn{4}{|l|}{ Betalactams } \\
\hline $\begin{array}{l}\text { Ceftolozan/tazobactam } \\
\text { (cephalosporin/betalactamase inhibitor) }\end{array}$ & P. aeruginosa, E. coli, K. pneumoniae, E. cloacae & ESBL, AmpC & $\begin{array}{l}\text { cIAl, cUTI, HABP, } \\
\text { VABP }\end{array}$ \\
\hline $\begin{array}{l}\text { Ceftazidim/avibactam } \\
\text { (cephalosporin/betalactamase inhibitor) }\end{array}$ & E. coli, K. pneumoniae, E. cloacae, P. aeruginosa & ESBL, KPC, AmpC, OXA & $\begin{array}{l}\text { cIAl, cUTI, HABP, } \\
\text { VABP }\end{array}$ \\
\hline $\begin{array}{l}\text { Ceftobiprole } \\
\text { (group } 5 \text { cephalosporin) }\end{array}$ & $\begin{array}{l}\text { S. aureus, E. faecalis, P. aeruginosa, E. coli, K. pneumo- } \\
\text { niae }\end{array}$ & MRSA & CABP, HABP \\
\hline $\begin{array}{l}\text { Cefiderocol } \\
\text { (siderophore cephalosporin) }\end{array}$ & $\begin{array}{l}\text { E. coli, K. pneumoniae, E. cloacae, P. aeruginosa, } \\
\text { Stenotrophomonas }\end{array}$ & ESBL, KPC, MBL, AmpC, OXA & cUTI \\
\hline $\begin{array}{l}\text { Meropenem/vaborbactam } \\
\text { (carbapenem/betalactamase inhibitor) }\end{array}$ & E. coli, K. pneumoniae, E. cloacae, P. aeruginosa & ESBL, KPC, AmpC & cUTI \\
\hline $\begin{array}{l}\text { Imipenem/cilastatin/relebactam } \\
\text { (carbapenem/betalactamase inhibitor) }\end{array}$ & E. coli, K. pneumoniae, E. cloacae, P. aeruginosa & ESBL, KPC, AmpC & cUTI, cIAl \\
\hline \multicolumn{4}{|l|}{ Tetracycline derivatives } \\
\hline $\begin{array}{l}\text { Eravacycline } \\
\text { (fluorocycline) }\end{array}$ & $\begin{array}{l}\text { E. coli, K. pneumoniae, E. cloacae, MRSA, E. faecium, } \\
\text { Acinetobacter }\end{array}$ & $\begin{array}{l}\text { Most MDR Enterobacteriaceae, } \\
\text { MRSA, VRE }\end{array}$ & CIAl \\
\hline \multicolumn{4}{|l|}{ Fluoroquinolones } \\
\hline $\begin{array}{l}\text { Delafloxacin } \\
\text { (fluoroquinolone) }\end{array}$ & $\begin{array}{l}\text { S. aureus, E. coli, K. pneumoniae, E. cloacae, P. aerugi- } \\
\text { nosa, E. faecalis }\end{array}$ & MRSA & SSSI, CABP \\
\hline
\end{tabular}




\section{Combinations of carbapenems with new betalactamase} inhibitors

Meropenem/vaborbactam is a combination of a wellknown carbapenem with the first boronic acid BLI. Vaborbactam inhibits Ambler class A and class C betalactamases, including KPC carbapenemases. Meropenem/vaborbactam is not active against pathogens with expression of class $\mathrm{B}(\mathrm{MBL})$ or class $\mathrm{D}$ betalactamases [20]. Similarly, the new BLI relebactam combined with imipenem/cilastatin accounts for stability against class A and class $\mathrm{C}$ betalactamases. Imipenem/cilastatin/relebactam is active against most KPC-producing CRE and carbapenem-resistant P. aeruginosa, but not A. baumannii or S. maltophilia [21]. Both new carbapenem-combinations offer an advantage compared to the monodrug only in the case of infections with the relevant MDR pathogens including certain CRE. Common indications are urinary and intraabdominal infections as well as HABP/VABP [22, 23].

\section{Ceftobiprole}

Ceftobiprole is a group-5 cephalosporin with activity against grampositive cocci including MRSA and vancomycin-resistant $\mathrm{E}$. faecalis, and gramnegative pathogens including $\mathrm{P}$. aeruginosa. It has been approved for treatment of CABP and HABP, but not for VABP [24].

\section{Cefiderocol}

Cefiderocol is a novel siderophore cephalosporin. Siderophores are used by bacteria for iron uptake. Thus, cefidercol exploits this mechanism to actively enter gramnegative bacteria where it exerts its antibiotic effects. The drug is stable against all ambler classes of betalactamases, making it potentially useful for treating infections with various enterobacteriaceae including CRE as well as MDR P. aeruginosa, A. baumannii and S. maltophilia $[25,26]$.

\section{Other antibiotics}

\section{Eravacycline}

Eravacycline is a novel fluorocycline, derived from tetracyclines. It has in-vitro activity against a wide spectrum of grampositive and gramnegative bacteria, as well as anaerobes. Eravacyclin is two- to fourfold more potent than tigecycline and is usually active against various MDR pathogens including MRSA, VRE and carbapenemase-producing enterobacteriacea and acinetobacter [16, 27]. P. aeruginosa and Burkholderia are intrinsically resistant. Eravacycline has been shown to be non-inferior to carbapenems for the treatment of complicated intraabdominal infections [28, 29]. As other tetracyclines, eravacycline is a primarily bacteriostatic antibiotic, which should be taken into account when treating severely neutropenic patients.

\section{Delafloxacin}

Delafloxacin is a fluoroquinolone with MRSA activity approved for CABP and skin/skin structure infections [30]. Its role in the treatment of febrile neutropenia has not been defined as yet and may be limited in patients that have received fluoroquinolone prophylaxis, and antibiotics from other classes would usually be preferred.

\section{Take home message}

In cancer patients with bacterial infections or febrile neutropenia, the risk for infections with MDR pathogens should be assessed before beginning empirical initial antibiotic therapy. Several new antibiotics are available for the treatment of MDR bacteria. For these new drugs knowledge of microbial resistance mechanisms and resistance testing is of pivotal importance for correct treatment choices.

Funding Open access funding provided by University of Innsbruck and Medical University of Innsbruck.

Conflict of interest G. Fritsche declares that he has no competing interests.

Open Access This article is licensed under a Creative Commons Attribution 4.0 International License, which permits use, sharing, adaptation, distribution and reproduction in any medium or format, as long as you give appropriate credit to the original author(s) and the source, provide a link to the Creative Commons licence, and indicate if changes were made. The images or other third party material in this article are included in the article's Creative Commons licence, unless indicated otherwise in a credit line to the material. If material is not included in the article's Creative Commons licence and your intended use is not permitted by statutory regulation or exceeds the permitted use, you will need to obtain permission directly from the copyright holder. To view a copy of this licence, visit http://creativecommons.org/licenses/by/4.0/.

\section{References}

1. Heinz WJ, Buchheidt D, Christopeit M, von LilienfeldToal M, Cornely OA, Einsele H, et al. Diagnosis and empirical treatment of fever of unknown origin (FUO) in adult neutropenic patients: guidelines of the infectious diseases working party (AGIHO) of the German society of hematology and medical oncology (DGHO). Ann Hematol. 2017;96:1775-92. https://doi.org/10.1007/s00277017-3098-3.

2. Montassier E, Batard E, Gastinne T, Potel G, de La Cochetière MF. Recent changes in bacteremia in patients with cancer: a systematic review of epidemiology and antibiotic resistance. Eur J Clin Microbiol Infect Dis. 2013;32:841-50. https://doi.org/10.1007/s10096-013-1819-7.

3. Martinez-Nadal G, Puerta-Alcalde P, Gudiol C, Cardozo C, Albasanz-Puig A, Marco F, et al. Inappropriate empirical antibiotic treatment in high-risk neutropenic patients with bacteremia in the era of multidrug resistance. Clin Infect Dis. 2020;70:1068-74. https://doi.org/10.1093/cid/ciz319.

4. Trecarichi EM, Tumbarello M. Antimicrobial-resistant Gram-negative bacteria in febrile neutropenic patients with cancer: current epidemiology and clinical impac. Curr 
Opin Infect Dis. 2014;27:200-10. https://doi.org/10.1097/ QCO.0000000000000038.

5. Rosa RG, Goldani LZ, dos Santos RP. Risk factors for multidrug-resistant bacteremia in hospitalized cancer patients with febrile neutropenia: a cohort study. Am J Infect Control. 2014;42:74-6. https://doi.org/10.1016/j.ajic.2013.06. 025.

6. Lalaoui R, Javelle E, Bakour S, Ubeda C, Rolain J-M. Infections due to carbapenem-resistant bacteria in patients with hematologic malignancies. Front Microbiol. 2020;11:1422. https://doi.org/10.3389/fmicb.2020.01422.

7. Kim Y-J, Jung SM, Kang J, Ryoo SM, Sohn CH, Seo D-W, et al Risk factors for extended-spectrum beta-lactamase-producing enterobacteriaceae infection causing septic shock in cancer patients with chemotherapy-induced febrileneutropenia. Intern Emerg Med. 2019;14:433-40. https://doi. org/10.1007/s11739-018-02015-x.

8. Harris PNA, Tambyah PA, Lye DC, Mo Y, LeeTH, Yilmaz M, et al. Effect of piperacillin-tazobactam vs meropenem on 30day mortality for patients with E coli or klebsiella pneumoniae bloodstream infection and ceftriaxone resistance: a randomized clinical trial. JAMA. 2018;320:984-94. https:// doi.org/10.1001/jama.2018.12163.

9. Doi Y. Treatment options for carbapenem-resistant Gram-negative bacterial infections. Clin Infect Dis. 2019;69:S565-S75. https://doi.org/10.1093/cid/ciz830.

10. Sheu C-C, Chang Y-T, Lin S-Y, Chen Y-H, Hsueh P-R. Infections caused by carbapenem-resistant enterobacteriaceae: an update on therapeutic options. Front Microbiol. 2019;10:80. https://doi.org/10.3389/fmicb.2019.00080.

11. Zhanel GG, GoldenAR, ZelenitskyS, Wiebe K, Lawrence CK, Adam HJ, et al. Cefiderocol: a siderophore cephalosporin with activity against carbapenem-resistant and multidrugresistant gram-negative bacilli. Drugs. 2019;79:271-89. https://doi.org/10.1007/s40265-019-1055-2.

12. Ko J-H, Kang C-I, Cornejo-Juárez P, Yeh K-M, Wang C-H, Cho SY, et al. Fluoroquinolones versus trimethoprimsulfamethoxazole for the treatment of stenotrophomonas maltophilia infections: a systematic review and metaanalysis. Clin Microbiol Infect. 2019;25:546-54. https:// doi.org/10.1016/j.cmi.2018.11.008.

13. Safdar A, Rolston KV. Stenotrophomonas maltophilia: changing spectrum of a serious bacterial pathogen in patients with cancer. Clin Infect Dis. 2007;45:1602-9. https://doi.org/10.1086/522998.

14. Hackel MA, Tsuji M, Yamano Y, Echols R, Karlowsky JA, Sahm DF. In vitro activity of the siderophore cephalosporin, cefiderocol, against carbapenem-nonsusceptible and multidrug-resistant isolates of gram-negative bacilli collected worldwide in 2014 to 2016. Antimicrob Agents Chemother. 2018; https://doi.org/10.1128/AAC.01968-17.

15. CillónizC, Dominedò C, TorresA. MultidrugresistantGramnegative bacteria in community-acquired pneumonia. Crit Care. 2019;23:79. https://doi.org/10.1186/s13054-0192371-3.

16. Seifert H, Stefanik D, Sutcliffe JA, Higgins PG. In-vitro activity of the novel fluorocycline eravacycline against carbapenem non-susceptible acinetobacter baumannii. Int J Antimicrob Agents. 2018;51:62-4. https://doi.org/10. 1016/j.ijantimicag.2017.06.022.

17. Torres A, Zhong N, Pachl J, Timsit J-F, Kollef M, Chen Z, et al. Ceftazidime-avibactam versus meropenem in nosocomial pneumonia, including ventilator-associated pneumonia (REPROVE): a randomised, double-blind, phase 3 noninferiority trial. Lancet Infect Dis. 2018;18:285-95. https:// doi.org/10.1016/S1473-3099(17)30747-8.
18. Carmeli Y, Armstrong J, Laud PJ, Newell P, Stone G, Wardman A, et al. Ceftazidime-avibactam or best available therapy in patients with ceftazidime-resistant enterobacteriaceae and pseudomonas aeruginosa complicated urinary tractinfections or complicated intra-abdominalinfections (REPRISE): a randomised, pathogen-directed, phase 3 study. Lancet Infect Dis. 2016;16:661-73. https://doi.org/ 10.1016/S1473-3099(16)30004-4.

19. Solomkin J, Hershberger E, Miller B, Popejoy M, Friedland I, Steenbergen J, et al. Ceftolozane/tazobactam plus metronidazole for complicated intra-abdominal infections in an era of multidrug resistance: results from a randomized, double-blind, phase 3 trial (ASPECT-cIAI). Clin Infect Dis. 2015;60:1462-71. https://doi.org/10.1093/cid/civ097.

20. Livermore DM, Mushtaq S. Activity of biapenem (RPX2003) combined with the boronate $\beta$-lactamase inhibitor RPX7009 against carbapenem-resistant enterobacteriaceae. JAntimicrob Chemother. 2013;68:1825-31. https:// doi.org/10.1093/jac/dkt118.

21. Livermore DM, Warner M, Mushtaq S. Activity of MK7655 combined with imipenem against enterobacteriaceae and pseudomonas aeruginosa. J Antimicrob Chemother. 2013;68:2286-90. https://doi.org/10.1093/jac/dkt178.

22. Titov I, Wunderink RG, Roquilly A, Rodríguez Gonzalez D, David-Wang A, Boucher HW, et al. A randomized, double-blind, multicenter trial comparing efficacy and safety of imipenem/cilastatin/relebactam versus piperacillin/ tazobactam in adults with hospital-acquired or ventilatorassociated bacterial pneumonia (RESTORE-IMI 2 study). Clin InfectDis. 2020; https:// doi.org/10.1093/cid/ciaa803.

23. WunderinkRG, Giamarellos-Bourboulis EJ, Rahav G, Mathers AJ, Bassetti M, Vazquez J, et al. Effect and safety of meropenem-vaborbactam versus best-available therapy in patients with carbapenem-resistant enterobacteriaceaeinfections: the TANGO II randomized clinical trial. Infect Dis Ther. 2018;7:439-55. https://doi.org/10.1007/s40121-0180214- 1.

24. Awad SS, Rodriguez AH, Chuang Y-C, Marjanek Z, Pareigis AJ, Reis G, et al. A phase 3 randomized double-blind comparison of ceftobiprole medocaril versus ceftazidime plus linezolid for the treatment of hospitalacquired pneumonia. Clin Infect Dis. 2014;59:51-61. https://doi.org/10.1093/cid/ciu219.

25. Bassetti M, Echols R, Matsunaga Y, Ariyasu M, Doi Y, Ferrer R, et al. Efficacy and safety of cefiderocol or best available therapy for the treatment of serious infections caused by carbapenem-resistant Gram-negative bacteria (CREDIBLE-CR): a randomised, open-label, multicentre, pathogen-focused, descriptive, phase 3 trial. Lancet Infect Dis. 2020; https://doi.org/10.1016/S1473-3099(20)307969.

26. Wunderink RG, Matsunaga Y, Ariyasu M, Clevenbergh P, Echols R, Kaye KS, et al. Cefiderocol versus highdose, extended-infusion meropenem for the treatment of Gram-negative nosocomial pneumonia (APEKS-NP): a randomised, double-blind, phase 3 , non-inferiority trial. Lancet Infect Dis. 2020; https://doi.org/10.1016/S14733099(20)30731-3.

27. Zhanel GG, Cheung D, Adam H, Zelenitsky S, Golden A, Schweizer F, et al. Review of eravacycline, a novel fluorocycline antibacterial agent. Drugs. 2016;76:567-88. https:// doi.org/10.1007/s40265-016-0545-8.

28. Solomkin J, Evans D, Slepavicius A, Lee P, Marsh A, Tsai L, et al. Assessing the efficacy and safety of eravacycline vs ertapenem in complicated intra-abdominal infections in the investigating gram-negative infections treated with eravacycline (IGNITE 1) trial: a randomized clinical trial. 
JAMA Surg. 2017;152:224-32. https://doi.org/10.1001/ jamasurg.2016.4237.

29. Solomkin JS, Gardovskis J, Lawrence K, Montravers P, Sway A, Evans D, et al. IGNITE4: results of a phase 3, randomized, multicenter, prospective trial of eravacycline vs meropenem in the treatment of complicated intraabdominal infections. Clin Infect Dis. 2019;69:921-9. https:// doi.org/10.1093/cid/ciy1029.

30. Horcajada JP, Salata RA, Álvarez-Sala R, Nitu FM, Lawrence L, Quintas $M$, et al. A phase 3 study to compare delafloxacin with moxifloxacin for the treatment of adults with community-acquired bacterial pneumonia (DEFINE-CABP). Open Forum Infect Dis. 2020;7:ofz514. https://doi.org/10.1093/ofid/ofz514.
Publisher's Note Springer Nature remains neutral with regard to jurisdictional claims in published maps and institutional affiliations.

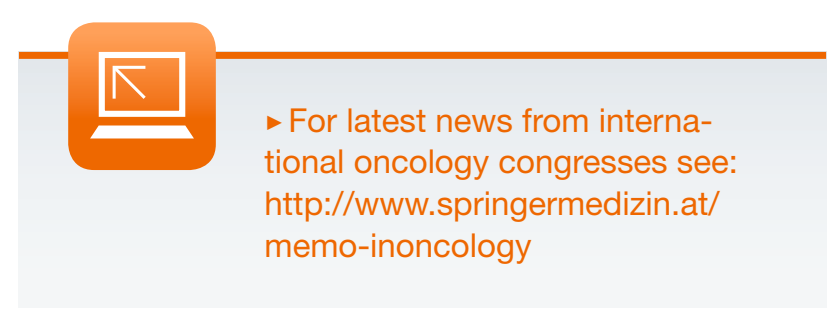

